\title{
Regional Economic Geography with Externalities, Congestion, and Fiscal Policies in a Small-Open Growth Economy
}

\author{
Wei-Bin Zhang \\ Ritsumeikan Asia Pacific University, Oita Prefecture, Japan \\ E-mail:wbz1@apu.ac.jp \\ Received July 21, 2010; revised August 23, 2010; accepted August 28, 2010
}

\begin{abstract}
This paper develops a two-regional growth model with amenity, capital accumulation and regional public goods with public goods and fiscal policies. The economy consists of two regions and each region consists of the industrial sector and public sector. The industrial sector provides goods in perfectly competitive markets. The public sector, which is financed by the regional government's tax incomes, supplies regional public goods. The public goods affect both firms and households. We show how to find equilibrium values of the dynamic system and simulate model. Then, we carry out comparative statics analysis with regard to parameter changes in tax rates, congestion and amenity. Our comparative statics analysis provides some important insights. For instance, a main difference between the effects of increasing the two regions' tax rates on the output is that as the technologically advanced region's (the other region's) tax rate on the industrial sector is increased, the national industrial output, national capital employed by the economy, and the national wealth are increased (reduced). In the region which increases the tax rate, the wage rate, consumption and wealth per capita, output per labor force, the population, and land rent are increased, and the corresponding variables in the other region are reduced.
\end{abstract}

Keywords: Small-Open Interregional Economy, Regional Fiscal Policies, Capital Accumulation, Endogenous Amenity, Public Goods

\section{Introduction}

The purpose of this study is to propose a model of interactions among economic growth, environmental changes, production externalities, public good supply with different fiscal policies. Regional scientists and regional economists have proposed various kinds of regional dynamic models [1-5]. It should also be remarked that there are many other models developed by regional scientists. For instance, some models based on the input-output system or/and the gravity theory are proposed to examine interregional trade patterns [6-12]. However, most of these models do not integrate the spatial factor satisfactorily from the theoretical point of view. This paper builds a dynamic model of interregional economies to show a way of analyzing the total spatial array of economic activities within a consistent framework.

This study analyzes a perfectly competitive economy with public goods and regional differentials in living co- nditions and productivity. The productivity advantages of one region may be offset to some extent by the higher wages that must be paid in a system where people are free to choose where they work and live. Higher wages are often associated with some kinds of disamenities (such as noise, pollutants, and densely populated neighborhood) and high living costs. Labor and capital are easily mobile between regions in industrialized economies. As capital mobility becomes high and costs associated with capital movement among regions become low, it is reasonable to assume that capital movement tends to equalize marginal productivities of capital among regions within a national economy. But there are different principles for analyzing temporary equilibrium conditions for labor movement in a dynamic regional framework. In this study, we determine population distribution by the condition of equalizing utility level. This paper is a generalization of the two-region growth model proposed by Zhang [13]. This paper generalizes the previous model in 
introducing different fiscal policies into the regional dynamic model. The previous models are limited to perfection competition without government intervention. In this study regional governments provide public goods with congestion. This paper is organized as follows. Section 2 defines the two region model with capital accumulation, externalities, public goods with congestion, and amenity. Section 3 shows how to determine equilibrium of variables. The simulation demonstrates existence of a unique equilibrium point of the dynamic system. Section 4 examines effects of changes in some parameters upon longterm national economic growth and economic geography. Section 5 concludes the study.

\section{The Two-Region Trade Model with Capital Accumulation}

This paper is concerned with a dynamic one-commodity and two-region trade model. It is assumed that the regions produce a homogenous commodity and public goods. It is assumed that there is only one (durable) good in the national economy under consideration. Households own assets of the economy and distribute their incomes to consume and save. Industrial sectors or firms use capital and labor. Industrial sectors sell their product to households or to other sectors and households sell their labor and assets to industrial sectors. Factor markets work well; factors are inelastically supplied and the available factors are fully utilized at every moment. Saving is undertaken only by households, which implies that all earnings of firms are distributed in the form of payments to factors of production. We omit the possibility of hoarding of output in the form of non-productive inventories held by households. All savings volunteered by households are absorbed by firms. We require saving and investment to be equal at any point of time.

The two regions are indexed by $j=1,2$. Perfect competition is assumed to prevail in good markets both within each region and between the regions, and commodities are traded without any barriers such as transport costs or tariffs. The labor markets are perfectly competitive within each region and between the regions. Let prices be measured in terms of the commodity and the price of the commodity be unity. We denote wage and interest rates by $w_{j}(t)$ and $r_{j}(t)$, respectively, in the $j$ th region. The interest rate is identical throughout the national economy, i.e., $r_{j}(t)=r^{*}$, where $r^{*}$ is the rate of interest fixed in the international economy. We assume a homogenous population. A person is free to choose his residential location. We assume that any person chooses the same region where he works and lives. Each region has fixed land. Land quality, climates, and environment are homogenous within each region, but they may vary among the regions. We neglect transportation cost of commodities between and within regions. As amenity and land are immobile, wage rates and land rent may not be equal between regions.

We introduce

$N$ - the given population of the economy;

$i$ and $p-$ subscript index for the industrial sector and public sector, respectively;

$L_{j}$ — the given (residential) area of region $j, j=1,2$;

$\tau_{i j}, \tau_{r j}$, and $\tau_{w j}$ - the fixed tax rates on the industrial output, interest income and wage income in region $j$;

$K(t)$ - the total capital stocks of the economy at time $t$

$K_{m j}(t)$ and $N_{m j}(t)$ - the capital stocks and labor force employed by region $j$ 's sector $m, m=i, p$;

$F_{m j}(t)$ - the output levels of sector $m$ in region $j$ at time $t$;

$l_{j}(t), \quad c_{j}(t)$ and $s_{j}(t)$ - per household's lot size, consumption level of commodity, and savings;

$w_{j}(t)$ and $R_{j}(t)$ - the wage rate and land rent in region $j$, respectively.

Behavior of producers

We assume that each firm chooses two productive factors, capital, $K_{j}(t)$, and labor, $N_{j}(t)$, at each point of time to maximize its profit, with the level of public goods in the region as given. The production functions are given by

$$
\begin{aligned}
& F_{i j}(t)=\Omega_{j}(t) K_{i j}^{\alpha_{i}}(t) N_{i j}^{\beta_{i}}(t), \\
& \alpha_{i}, \beta_{i} \geq 0, \quad \alpha_{i}+\beta_{i}=1, \quad j=1,2,
\end{aligned}
$$

where $\Omega_{j}(t)$ is a function of externalities, public service and congestion. We specify $\Omega_{j}(t)$ as follows

$$
\Omega_{j}(t)=A_{i j} F_{p j}^{\theta_{p}} K_{i j}^{\theta_{e}}(t)\left(\frac{K_{p j}(t)}{K_{i j}(t)}\right)^{\theta_{c}}, A_{i}, \theta_{p}, \theta_{e}, \theta_{c} \geq 0,
$$

where $F_{p j}^{\theta_{p}}(t)$ measures the effect of public service on the region's productivity, $K_{i j}^{\theta_{e}}(t)$ the effect of externalities, and $\left(K_{p j}(t) / K_{i j}(t)\right) \theta_{c}$ the effect of congestion of public goods. Similar to [14], we interpret that when $\theta_{e}=$ $\theta_{c}=0$, there is neither congestion nor externality. The nonrival and nonexcludable public service is available equally to each agent, independent of the usage of others. Obviously this is a limited case as most of public services are subject to some degree of congestion. We take account of congestion effects by the term, $\left(K_{p j}(t) / K_{i j}(t)\right)^{\theta_{c}}$, which implies that for a fixed level of public capital, a rise in the private capital tends to reduce the efficiency of public services. There are different ways of describing congestion [15]. Here we neglect possible congestion effects due to the region's population and consumption activities. 
Markets are competitive; thus labor and capital earn their marginal products, and firms earn zero profits. The rate of interest, $r^{*}$, and wage rates, $w_{j}(t)$, are determined by markets. Hence, for any individual firm $r^{*}$ and $w_{j}(t)$ are given at each point of time. Let $\delta_{k}$ stand for the depreciation rate of physical capital and $\bar{\tau}_{i j} \equiv 1-\tau_{i j}$. The marginal conditions are given by

$$
r^{*}+\delta_{k}=\frac{\alpha_{i} \bar{\tau}_{i j} F_{i j}}{K_{i j}}, \quad w_{j}=\frac{\beta_{i} \bar{\tau}_{i j} F_{i j}}{N_{i j}} .
$$

Behavior of consumers

Each worker may get income from land ownership, wealth ownership and wages. In order to define incomes, it is necessary to determine land ownership structure. It can be seen that land properties may be distributed in multiple ways under various institutions. This study assumes the absentee land ownership. It should be noted that another two popular assumptions in the literature of urban economics are the equally shared landownership and the public ownership. For instance as accepted in Kanemoto the city government rents the land from the landowners at certain rent and sublets it to households at the market rent, using the net revenue to subsidize city residents equally [16]. Hochman considers a mixture of absentee and equally shared ownerships [17]. Different ownerships may have different effects on interregional dynamics. The topic about how different land ownerships may affect interregional dynamics will be examined in the future. Land is owned by absentee landlords who spend their land incomes outside the economic system. This study uses the approach to consumers' behavior proposed by Zhang in the early 1990s. As demonstrated systematically in $[5,18]$, this approach makes it possible to solve many important (national) economic problems, such as growth problems with heterogeneous households, which are analytically intractable by the traditional approaches in economics. Let $\bar{k}_{j}(t)$ stand for the per capita wealth in region $j$. Each consumer of region $j$ obtains income

$$
y_{j}(t)=\bar{\tau}_{r j} r^{*} \bar{k}_{j}(t)+\bar{\tau}_{w j} w_{j}(t)
$$

from the interest payment, $\bar{\tau}_{r j} r^{*} \bar{k}_{j}$, and the wage payment, $\quad \bar{\tau}_{w j} w_{j}$, where $\bar{\tau}_{r j} \equiv 1-\tau_{r j}$ and $\bar{\tau}_{w j} \equiv 1-\tau_{w j}$. The disposable income is given by

$$
\hat{y}_{j}(t)=y_{j}(t)+\bar{k}_{j}(t)
$$

At each point of time, a consumer distributes the total available budget among housing, $l_{j}(t)$, saving, $s_{j}(t)$, consumption of goods, $c_{j}(t)$. The budget constraint is given by

$$
R_{j} l_{j}+c_{j}+s_{j}=\hat{y}_{j}=\bar{\tau}_{r j} r^{*} \bar{k}_{j}+\bar{\tau}_{w j} w_{j}+\bar{k}_{j} .
$$

We assume that utility level that the consumers obtain is dependent on $l_{j}(t), c_{j}(t)$, and $s_{j}(t)$. The utility level of the consumer in region $j, U_{j}(t)$, is specified as follows

$$
\begin{aligned}
& U_{j}(t)=\theta_{j}(t) F_{p j}^{v_{h}}(t) l_{j}^{\eta_{h}}(t) c_{j}^{\xi_{h}}(t) s_{j}^{\lambda_{h}}(t), \\
& v_{h}, \eta_{h}, \xi_{h}, \lambda_{h}>0,
\end{aligned}
$$

in which $v_{h}, \eta_{h}, \xi_{h}$, and $\lambda_{h}$ are a typical person's elasticity of utility with regard to lot size, commodity and savings in region $j$. We call $\eta_{h}, \xi_{h}$, and $\lambda_{h}$ propensities to consume lot size, to consume goods, and to hold wealth (save), respectively. We assume that households would like to have more public goods with the other things fixed, that is, $v_{h}>0$. In (6), $\theta_{j}(t)$ is called region $j$ 's amenity level. In this study, we specify $\theta_{j}$ as follows

$$
\theta_{j}(t)=\bar{\theta}_{j} N_{j}^{b}(t)
$$

where $\bar{\theta}_{j}(>0)$ are positive parameters and $b$ is a parameter. We don't specify the sign of $b$ as the population may have either positive or negative effects on regional attractiveness. Maximizing $U_{j}(t)$ subject to the budget constraints (5) yields

$$
l_{j}(t) R_{j}(t)=\eta \hat{y}_{j}(t), c_{j}(t)=\xi \hat{y}_{j}(t), s_{j}(t)=\lambda \hat{y}_{j}(t),
$$

in which

$$
\eta \equiv \frac{\eta_{h}}{\eta_{h}+\xi_{h}+\lambda_{h}}, \xi \equiv \frac{\xi_{h}}{\eta_{h}+\xi_{h}+\lambda_{h}}, \lambda \equiv \frac{\lambda_{h}}{\eta_{h}+\xi_{h}+\lambda_{h}} .
$$

According to the definitions of $s_{j}(t)$, the wealth accumulation of the representative person in region $j$ is given by

$$
\dot{\overline{k_{j}}}(t)=s_{j}(t)-\bar{k}_{j}(t) .
$$

As households are assumed to be freely mobile between the regions, the utility level of people should be equal, irrespective of in which region they live, i.e.

$$
U_{1}(t)=U_{2}(t) .
$$

We now describe the public sector. In this model, we assume that the public sector is financially supported by the regional government's tax income. The capital stocks and workers employed by the public sector are paid at the same rates that the private sector pays the services of these factors. We assume that the regional governments behave effectively in the sense that they use the tax income to maximize public services. The production of public services is to combine capital, $K_{p j}(t)$, and labor force, $N_{p j}(t)$, as follows

$$
F_{p j}(t)=A_{p j} K_{p j}^{\alpha_{0 p}}(t) N_{p j}^{\beta_{0 p}}(t), \alpha_{0 p}, \beta_{0 p}, A_{p j}>0 .
$$

Let $Y_{p j}(t)$ stand for government $j$ 's tax income. Then we have

$$
Y_{p j}(t)=\tau_{i j} F_{i j}(t)+\tau_{r j} r^{*} \bar{k}_{j}(t) N_{j}(t)+\tau_{w j} w_{j}(t) N_{j}(t),(12)
$$


where $\tau_{i j} F_{i j}, \quad \tau_{r j} r \bar{k}_{j} N_{j}$ and $\tau_{w j} w_{j} N_{j}$ are respectively the tax incomes from the production sector's output, the households' interest payments and the households' wage incomes.

The public sector in region $j$ is faced with the following budget constraint

$$
w_{j}(t) N_{p j}(t)+\left(r^{*}+\delta_{k}\right) K_{p j}(t)=Y_{p j}(t) .
$$

Maximization of public services under the budget constraint yields

$$
\left(r^{*}+\delta_{k}\right) K_{p j}=\alpha_{p} Y_{p j}, \quad w_{j} N_{p j}=\beta_{p} Y_{p j},
$$

in which

$$
\alpha_{p} \equiv \frac{\alpha_{0 p}}{\alpha_{0 p}+\beta_{0 p}}, \quad \beta_{p} \equiv \frac{\beta_{0 p}}{\alpha_{0 p}+\beta_{0 p}} .
$$

The total capital stock employed by the economy is equal to the total capitals employed by all the regions. That is

$$
K(t)=\sum_{j=1}^{2}\left\{K_{i j}(t)+K_{p j}(t)\right\}=\sum_{j=1}^{2} K_{j}(t),
$$

where $K_{j}(t) \equiv K_{i j}(t)+K_{p j}(t)$. The assumption that labor force and land are fully employed is represented by

$$
\sum_{j=1}^{2} N_{j}(t)=N, l_{j}(t) N_{j}(t)=L_{j}, \quad j=1,2,
$$

where $N_{j}(t)=N_{i j}(t)+N_{p j}(t)$.

The total wealth of the national economy is the sum of the wealth owned by all the households

$$
\bar{K}(t)=\sum_{j=1}^{2} \bar{k}_{j}(t) N_{j}(t) .
$$

We introduce $B(t)$ as the value of the economy's net foreign assets at $t$. The income from the net foreign assets, $E(t)$, which may be either positive, zero, or negative, is equal to $r^{*} B(t)$. According to the definitions of the national wealth, the capital stocks employed by the economy and the net foreign assets, we have $\bar{K}(t)=$ $K(t)+B(t)$. A country's current balance at time $t$ is the change in the value of its net claims over the rest of the world - the change in its net foreign assets. If $\dot{B}(t)>0$, the economy as a whole is lending (in this case we say that the current account balance is in surplus); if $\dot{B}(t)$ $<0$, the economy as a whole is borrowing (the current account balance is in deficit); and if $\dot{B}(t)=0$, the economy as a whole is neither borrowing nor lending (the current account balance is in balance). We have thus built the model with endogenous capital accumulation and regional capital and labor distribution. We now examine spatial equilibrium and effects of changes in different conditions upon the economic geography.

\section{Economic Equilibrium}

As it is difficult to examine all the dynamic properties of the regional economy, we are only concerned with steady states. By (9), we have $s_{j}=\bar{k}_{j}$ at steady state. From this equation and $s_{j}=\lambda \hat{y}_{j}$, we have $\hat{y}_{j}=\bar{k}_{j} / \lambda$. From (2) and (14), we solve

$$
\widetilde{k}_{j} \equiv \frac{K_{p j}}{K_{i j}}=\frac{\alpha N_{p j}}{N_{i j}},
$$

where $\alpha \equiv \alpha_{p} \beta_{i} / \alpha_{i} \beta_{p}$. From this equation, $N_{j}=N_{i j}$ $+N_{p j}$ and $K_{j}=K_{i j}+K_{p j}$, we solve

$$
\begin{gathered}
N_{i j}=\frac{\alpha N_{j}}{\alpha+\widetilde{k}_{j}}, N_{p j}=\frac{\widetilde{k}_{j} N_{j}}{\alpha+\widetilde{k}_{j}}, \\
K_{i j}=\frac{K_{j}}{1+\widetilde{k}_{j}}, K_{p j}=\frac{\widetilde{k}_{j} K_{j}}{1+\widetilde{k}_{j}} .
\end{gathered}
$$

From the definition of $\Omega_{j}$, (11) and (18), we can express the production functions as follows

$$
F_{i j}=\frac{\bar{A}_{j} \tilde{k}_{j}^{\bar{\theta}} K_{j}^{\bar{\alpha}} N_{j}^{\bar{\beta}}}{\left(1+\tilde{k}_{j}\right)^{\bar{\alpha}}\left(\alpha+\tilde{k}_{j}\right)^{\bar{\beta}}},
$$

where

$$
\begin{aligned}
& \bar{\theta} \equiv \theta_{p} \alpha_{0 p}+\theta_{c}+\theta_{p} \beta_{0 p}, \bar{\alpha} \equiv \alpha_{i}+\theta_{e}+\theta_{p} \alpha_{0 p}, \\
& \bar{\beta} \equiv \beta_{i}+\theta_{p} \beta_{0 p}, \bar{A}_{j} \equiv A_{i j} A_{p j}^{\theta_{p}} \alpha^{\beta_{i}} .
\end{aligned}
$$

From (1), (18) and (19), we have

$$
\begin{gathered}
r^{*}+\delta_{k}=\frac{\alpha_{i} \bar{\tau}_{i j} \bar{A}_{j} \tilde{k}_{j}^{\bar{\theta}} K_{j}^{\bar{\alpha}-1} N_{j}^{\bar{\beta}}}{\left(1+\tilde{k}_{j}\right)^{\bar{\alpha}-1}\left(\alpha+\tilde{k}_{j}\right)^{\bar{\beta}}}, \\
w_{j}=\frac{\left(r^{*}+\delta_{k}\right) \beta_{i} K_{j}\left(\alpha+\tilde{k}_{j}\right)}{\alpha \alpha_{i} N_{j}\left(1+\tilde{k}_{j}\right)} .
\end{gathered}
$$

From the definition of $\hat{y}_{j}$ and $\hat{y}_{j}=\bar{k}_{j} / \lambda$, we solve $w_{j}=r_{j}^{*} \bar{k}_{j}$, where

$$
r_{j}^{*} \equiv \frac{1 / \lambda-1-\bar{\tau}_{r j} r^{*}}{\bar{\tau}_{w j}} .
$$

From $w_{j}=r_{j}^{*} \bar{k}_{j}$ and (20)

$$
\bar{k}_{j}=\frac{\left(r^{*}+\delta_{k}\right) \beta_{i} K_{j}\left(\alpha+\tilde{k}_{j}\right)}{\alpha \alpha_{i} r_{j}^{*} N_{j}\left(1+\tilde{k}_{j}\right)} .
$$

From the marginal conditions for capital in (20), we have $K_{2}=\Lambda_{K} K_{1}$, where

$$
\Lambda_{K} \equiv\left[\frac{\bar{\tau}_{i 1} \bar{A}_{1} \tilde{k}_{1}^{\bar{\theta}} N_{1}^{\bar{\beta}}\left(\alpha+\tilde{k}_{2}\right)^{\bar{\beta}}}{\bar{\tau}_{i 2} \bar{A}_{2} \tilde{k}_{2}^{\bar{\theta}} N_{2}^{\bar{\beta}}\left(\alpha+\tilde{k}_{1}\right)^{\bar{\beta}}}\right]^{1 /(\bar{\alpha}-1)} \frac{1+\tilde{k}_{2}}{1+\tilde{k}_{1}} .
$$


From $K_{2}=\Lambda_{K} K_{1}$ and $K_{1}+K_{2}=K$, we have

$$
K_{1}=\frac{K}{1+\Lambda_{K}}, K_{2}=\frac{\Lambda_{K} K}{1+\Lambda_{K}} .
$$

Insert $l_{j}=L_{j} / N_{j}, c_{j}=\xi \hat{y}_{j}$, and $s_{j}=\lambda \hat{y}_{j}$ in the utility function

$$
\begin{aligned}
U_{j}= & \bar{\theta}_{j} \xi^{\xi_{h}} \lambda^{-\xi_{h}} A_{p j}^{v_{h}} L_{j}^{\eta_{h}} \\
& \frac{K_{j}^{v_{h} \alpha_{0 p}} \tilde{k}_{j}^{v_{h} \beta_{0 p}+v_{h} \alpha_{0 p}} N_{j}^{b-\eta_{h}+v_{h} \beta_{0 p}} \bar{k}_{j}^{\xi_{h}+\lambda_{h}}}{\left(\alpha+\tilde{k}_{j}\right)^{v_{h} \beta_{0 p}}\left(1+\tilde{k}_{j}\right)^{v_{h} \alpha_{0 p}}}
\end{aligned}
$$

where we use (7), (11) and $\hat{y}_{j}=\bar{k}_{j} / \lambda$. From (23), (21) and $U_{1}=U_{2}$, we have $N_{2}=\Lambda_{N} N_{1}$, where

$$
\begin{aligned}
\Lambda_{N}\left(\widetilde{k}_{1}, \widetilde{k}_{2}\right) \equiv & \theta_{u}\left(\frac{\widetilde{k_{1}}}{\widetilde{k}_{2}}\right)^{\left[v_{h} \beta_{0 p}+v_{h} \alpha_{0 p}-\bar{\theta} \xi_{u} /(\bar{\alpha}-1)\right] \lambda_{u}} \\
& \left(\frac{\alpha+\widetilde{k}_{2}}{\alpha+\widetilde{k}_{1}}\right)^{\left[v_{h} \beta_{0 p}-\xi_{h}-\lambda_{h}-\bar{\beta} \xi_{u} /(\bar{\alpha}-1)\right] \lambda_{u}},
\end{aligned}
$$

where

$$
\begin{aligned}
\xi_{u} & \equiv v_{h} \alpha_{0 p}+\xi_{h}+\lambda_{h}, \lambda_{u} \\
& \equiv\left(b-\eta_{h}+v_{h} \beta_{0 p}-\xi_{h}-\lambda_{h}-\frac{\xi_{u} \bar{\beta}}{\bar{\alpha}-1}\right)^{-1}, \\
\theta_{u} & \equiv\left[\frac{r_{2}^{*\left(\xi_{h}+\lambda_{h}\right)} \bar{\theta}_{1} A_{p 1}^{v_{h}} L_{1}^{\eta_{h}}}{r_{1}^{*\left(\xi_{h}+\lambda_{h}\right)} \bar{\theta}_{2} A_{p 2}^{v_{h}} L_{2}^{\eta_{h}}}\right]^{\lambda_{u}} \\
& \left(\frac{\bar{\tau}_{i 2} \bar{A}_{2}}{\bar{\tau}_{i 1} \bar{A}_{1}}\right)^{\xi_{u} \lambda_{u} /(\bar{\alpha}-1)} .
\end{aligned}
$$

From $N_{2}=\Lambda_{N} N_{1}$ and the full labor employment condition, we have

$$
N_{1}=\frac{N}{1+\Lambda_{N}}, \quad N_{2}=\frac{\Lambda_{N} N}{1+\Lambda_{N}} .
$$

From the definition of $\Lambda_{K}$ and (23)

$$
\Lambda_{K}\left(\tilde{k}_{1}, \tilde{k}_{2}\right)=\left[\frac{\bar{\tau}_{i 1} \bar{A}_{1} \tilde{k}_{1}^{\bar{\theta}}\left(\alpha+\tilde{k}_{2}\right)^{\bar{\beta}}}{\bar{\tau}_{i 2} \bar{A}_{2} \tilde{k}_{2}^{\bar{\theta}} \Lambda_{N}^{\bar{\beta}}\left(\alpha+\tilde{k}_{1}\right)^{\bar{\beta}}}\right]^{1 /(\bar{\alpha}-1)} \frac{1+\tilde{k}_{2}}{1+\tilde{k}_{1}}
$$

From (14) and (18), we have

$$
K_{j}=\frac{\alpha_{p}\left(1+\tilde{k}_{j}\right)}{\left(r^{*}+\delta_{k}\right) \tilde{k}_{j}} Y_{p j} .
$$

From the definition of $Y_{p j}$, we have

$$
Y_{p j}=\left(\frac{\alpha \tau_{i j} r_{j}^{*}}{\beta_{i} \bar{\tau}_{i j}\left(\alpha+\tilde{k}_{j}\right)}+\tau_{r j} r^{*}+\tau_{w j} r_{j}^{*}\right) \bar{k}_{j} N_{j},
$$

where we use $F_{i j}=w_{j} N_{i j} / \beta_{i} \bar{\tau}_{i j}, \quad w_{j}=r_{j}^{*} \bar{k}_{j}$, and the equation for $N_{i j}$ in (18). Substituting (27) into (26) yields

$$
\begin{gathered}
\tilde{k}_{j}=\left(\frac{\alpha \tau_{i j} r_{j}^{*}}{\beta_{i} \bar{\tau}_{i j}}+\alpha\left(\tau_{r j} r^{*}+\tau_{w j} r_{j}^{*}\right)\right) \\
\left(\frac{r_{j}^{*}}{\beta_{p}}-\tau_{r j} r^{*}-\tau_{w j} r_{j}^{*}\right)^{-1} .
\end{gathered}
$$

The above equations determine the equilibrium values of $\widetilde{k}_{j}$. The following lemma describes a procedure to determine the equilibrium values of all the variables.

\section{Lemma 1}

For a given rate of interest in the global market, the national economy has a unique equilibrium point. The equilibrium values of all the variables are given by the following procedure: $\widetilde{k}_{j}$ by (28) $\rightarrow N_{j}$ by (24) $\rightarrow N_{i j}$ and $N_{p j}$ by (18) $\rightarrow K_{j}$ by the marginal conditions for capital in (20) $\rightarrow K=K_{1}+K_{2} \rightarrow w_{j}$ by (20) $\rightarrow K_{i j}$ and $K_{p j}$ by (18) $\rightarrow Y_{p j}$ by (27) $\rightarrow F_{i j}$ by (19) $\rightarrow$ $F_{p j}$ by $(11) \rightarrow \bar{k}_{j}$ by $(21) \rightarrow \hat{y}_{j}$ by $(5) \rightarrow l_{j}=$ $L_{j}^{p j} / N_{j} \rightarrow \bar{K}$ by $(17) \rightarrow B=\bar{K}-K \rightarrow R_{j}=\eta \hat{y}_{j}$ $/ l_{j} \rightarrow c_{j}$ and $s_{j}$ by (8) $\rightarrow C_{j}=c_{j} N_{j}$ and $S_{j}=$ $s_{j} N_{j} \rightarrow U_{j}$ by (6).

To simulate the model, we specify the parameter values as follows

$$
\begin{aligned}
& r^{*}=0.05, \quad \alpha_{i}=0.3, \quad \alpha_{0 p}=0.3, \quad \beta_{0 p}=0.4, \\
& \theta_{c}=0.05, \quad \theta_{p}=0.04, \quad \theta_{e}=0.03, \\
& A_{i 1}=1.2, \quad A_{i 2}=1, \quad A_{p 1}=1.1, \quad A_{p 2}=1, \\
& b=-0.1, \quad \bar{\theta}_{1}=3, \quad \bar{\theta}_{2}=4, \quad \delta_{k}=0.05, \\
& \xi_{h}=0.09, \quad \lambda_{h}=0.8, \quad \eta_{h}=0.09, \\
& v_{h}=0.05, \quad N=10, \quad L_{1}=3, \quad L_{2}=4, \\
& \tau_{i 1}=\tau_{r 1}=\tau_{w 1}=0.04, \quad \tau_{i 2}=\tau_{r 2}=\tau_{w 2}=0.03 .
\end{aligned}
$$

The rate of interest is fixed at 5 percent in international market. The total population is 10 . The productivity parameter, $A_{i l}$, is higher than region 2 . The productivity parameters of the public sectors in the two regions are equal. We consider that Region 1 is technologically more advanced than region 2 . Region 1 ' and 2 ' amenity parameters, $\bar{\theta}_{1}$ and $\bar{\theta}_{2}$, are different, the value in region 1 being lower than region 2. Region 1 's land for housing is less than region 2 ' land. The proopensity to consume public goods, $v_{h}$, is lower than the propensity to consume the industrial goods, $\xi_{h}$, and the propensity to consume the lot size, $\lambda_{h}$. The tax rates on the output level, the income from wealth and wage income are the same within each region and the tax rates in region 1 are higher than the tax rates region 2 . The externality and congestion parameters, $\theta_{e}$ and $\theta_{c}$, are positive. It should be remarked that although the 
specified values are not based on empirical observations, the choice does not seem to be unrealistic. For instance, some empirical studies on the US economy demonstrate that the value of the parameter, $\alpha$, in the Cobb-Douglas production is approximately equal to $0.3[19,20]$. With regard to the technological parameters, what are important in our interregional study are their relative values. The presumed productivity differences among the regions are not very large. This similarly holds for the specified differences in the amenity parameters among regions.

Following the procedure in Lemma 1, we calculate the equilibrium values of all the variables. We list the simulation results as follows

$$
\begin{aligned}
& F=18.39, K=58.90, \bar{K}=71.43, \\
& B=12.53, \overline{k_{1}}=7.51, \bar{k}_{2}=4.77, \\
& \left(\begin{array}{l}
N_{1} \\
N_{i 1} \\
N_{p 1}
\end{array}\right)=\left(\begin{array}{l}
8.65 \\
8.12 \\
0.53
\end{array}\right),\left(\begin{array}{l}
N_{2} \\
N_{i 2} \\
N_{p 2}
\end{array}\right)=\left(\begin{array}{l}
1.35 \\
1.29 \\
0.06
\end{array}\right), \\
& \left(\begin{array}{l}
K_{1} \\
K_{i 1} \\
K_{p 1}
\end{array}\right)=\left(\begin{array}{l}
53.72 \\
48.24 \\
5.48
\end{array}\right),\left(\begin{array}{l}
K_{2} \\
K_{i 2} \\
K_{p 2}
\end{array}\right)=\left(\begin{array}{l}
5.18 \\
4.78 \\
0.40
\end{array}\right), \\
& \left(\begin{array}{l}
F_{i 1} \\
F_{i 2} \\
F_{p 1} \\
F_{p 2}
\end{array}\right)=\left(\begin{array}{l}
16.75 \\
1.64 \\
1.42 \\
0.25
\end{array}\right),\left(\begin{array}{l}
f_{i 1} \\
f_{i 2} \\
y_{p 1} \\
y_{p 2}
\end{array}\right)=\left(\begin{array}{l}
1.94 \\
1.22 \\
0.15 \\
0.07
\end{array}\right), \\
& \left(\begin{array}{l}
w_{1} \\
w_{2} \\
R_{1} \\
R_{2}
\end{array}\right)=\left(\begin{array}{l}
1.39 \\
0.87 \\
2.44 \\
0.18
\end{array}\right),\left(\begin{array}{l}
c_{1} \\
c_{2} \\
l_{1} \\
l_{2}
\end{array}\right)=\left(\begin{array}{l}
0.85 \\
0.54 \\
0.35 \\
2.97
\end{array}\right) .
\end{aligned}
$$

In (19), the variables, $f_{i j}$ and $y_{p j}$, are respectively the output level per worker and the expenditure on public goods per resident in region $j$ defined as

$$
f_{i j}=\frac{F_{i j}}{N_{i j}}, \quad y_{p j}=\frac{Y_{p j}}{N_{j}}, j=1,2 .
$$

More than half of the national population and capital are located in region 1. The per-capita levels of wealth and consumption and wage rate in region 1 are much higher than the corresponding variables in regions 2 . The lot size of region 2 is larger than in region 1 . The consumption level per capita in region 1 is higher than in region 2. We see that although workers can earn more money in the advanced region than in the other region, they have to pay much higher rent for housing than the households in the other region. Expectably, the typical household in the advanced region consumes more goods and lives in a smaller house than the typical household in region 2. Mainly because of its technological advantage, the advanced region attracts far more workers and capital than the other region.

\section{Parameter Changes and Economic Geography}

First, we examine effects of change in the total productivity of region 2 's industrial sector, $A_{i 2}$. We introduce a symbol, $\bar{\Delta}$, by which a variable, $\overline{\Delta x}$, stand for the change rate of the variable, $x$, in percentage due to changes in parameter value. We increase $A_{i 2}$ from 1 to 1.1, keeping all the other parameter values as specified in (29). The simulation results are illustrated in (30)

$$
\begin{aligned}
& A_{i 2}: 1 \Rightarrow 1.1, \bar{\Delta} F=\bar{\Delta} K=\bar{\Delta} \bar{K}=-6.39, \\
& \bar{\Delta} B=-2.256, \bar{\Delta} \bar{k}_{1}=-4.24, \bar{\Delta} \bar{k}_{2}=-29.06, \\
& \left(\begin{array}{l}
\bar{\Delta} N_{1} \\
\bar{\Delta} N_{i 1} \\
\bar{\Delta} N_{p 1}
\end{array}\right)=\left(\begin{array}{l}
-38.82 \\
-38.82 \\
-38.82
\end{array}\right),\left(\begin{array}{l}
\bar{\Delta} N_{2} \\
\bar{\Delta} N_{i 2} \\
\bar{\Delta} N_{p 2}
\end{array}\right)=\left(\begin{array}{l}
249.45 \\
249.45 \\
249.45
\end{array}\right), \\
& \left(\begin{array}{l}
\bar{\Delta} K_{1} \\
\bar{\Delta} K_{i 1} \\
\bar{\Delta} K_{p 1}
\end{array}\right)=\left(\begin{array}{l}
-41.41 \\
-41.41 \\
-41.41
\end{array}\right),\left(\begin{array}{l}
\bar{\Delta} K_{2} \\
\bar{\Delta} K_{i 2} \\
\bar{\Delta} K_{p 2}
\end{array}\right)=\left(\begin{array}{l}
351.01 \\
351.01 \\
351.01
\end{array}\right), \\
& \left(\begin{array}{l}
\bar{\Delta} F_{i 1} \\
\bar{\Delta} F_{i 2} \\
\bar{\Delta} F_{p 1} \\
\bar{\Delta} F_{p 2}
\end{array}\right)=\left(\begin{array}{c}
-41.41 \\
351.01 \\
-30.02 \\
159.19
\end{array}\right),\left(\begin{array}{l}
\bar{\Delta} f_{i 1} \\
\bar{\Delta} f_{i 2} \\
\bar{\Delta} y_{p 1} \\
\bar{\Delta} y_{p 2}
\end{array}\right)=\left(\begin{array}{c}
-4.24 \\
29.06 \\
-4.24 \\
29.06
\end{array}\right), \\
& \left(\begin{array}{l}
\bar{\Delta} w_{1} \\
\bar{\Delta} w_{2} \\
\bar{\Delta} R_{1} \\
\bar{\Delta} R_{2}
\end{array}\right)=\left(\begin{array}{c}
-4.23 \\
29.06 \\
-41.41 \\
351.01
\end{array}\right),\left(\begin{array}{l}
\bar{\Delta} c_{1} \\
\bar{\Delta} c_{2} \\
\bar{\Delta} l_{1} \\
\bar{\Delta} l_{2}
\end{array}\right)=\left(\begin{array}{c}
-4.24 \\
29.06 \\
63.45 \\
-71.38
\end{array}\right) .
\end{aligned}
$$

As region 2 's total productivity is increased, the national output, wealth and capital employed are reduced. As region 2's productivity is increased, the region's wage rate is increased and the region becomes more attractive. People immigrate to region 2 from region 1 . As region 2 's productivity after the change, $A_{\mathrm{i} 2}=1.1$, is still lower than 1 's productivity, $A_{i 1}=1.2$, the net result of the reallocation of the population reduces the national output level.

We now examine effects of change in the tax rate on the production sector. We increase $\tau_{i 1}$ from 4 percent to 5 percent. As the tax rate is increased, the industrial output, total capital employed by the economy, and the 
total wealth are increased. The wage rate, consumption per capita, wealth per capita, output per labor force and public expenditure per capita in region 1 are increased. In region 2 the wage rate, consumption per capita, wealth per capita, and output per labor force are reduced. Although the region's output and total wealth are reduced, its public expenditure per capita is increased. This occurs because a large portion of the region population move to region 1 as region 1's population is increased, its land rent rises and lot size falls.

$$
\begin{aligned}
& \tau_{i 1}: 0.04 \Rightarrow 0.05, \bar{\Delta} F=0.52, \bar{\Delta} K=0.88, \\
& \bar{\Delta} \bar{K}=0.34, \bar{\Delta} B=-2.22, \bar{\Delta} \bar{k}_{1}=0.12, \\
& \bar{\Delta} \bar{k}_{2}=-0.48, \\
& \left(\begin{array}{l}
\bar{\Delta} N_{1} \\
\bar{\Delta} N_{i 1} \\
\bar{\Delta} N_{p 1}
\end{array}\right)=\left(\begin{array}{c}
0.83 \\
-0.04 \\
14.15
\end{array}\right),\left(\begin{array}{l}
\bar{\Delta} N_{2} \\
\bar{\Delta} N_{i 2} \\
\bar{\Delta} N_{p 2}
\end{array}\right)=\left(\begin{array}{l}
-5.33 \\
-5.33 \\
-5.33
\end{array}\right), \\
& \left(\begin{array}{l}
\bar{\Delta} K_{1} \\
\bar{\Delta} K_{i 1} \\
\bar{\Delta} K_{p 1}
\end{array}\right)=\left(\begin{array}{c}
1.53 \\
0.08 \\
14.29
\end{array}\right),\left(\begin{array}{l}
\bar{\Delta} K_{2} \\
\bar{\Delta} K_{i 2} \\
\bar{\Delta} K_{p 2}
\end{array}\right)=\left(\begin{array}{l}
-5.79 \\
-5.79 \\
-5.79
\end{array}\right), \\
& \left(\begin{array}{l}
\bar{\Delta} F_{i 1} \\
\bar{\Delta} F_{i 2} \\
\bar{\Delta} F_{p 1} \\
\bar{\Delta} F_{p 2}
\end{array}\right)=\left(\begin{array}{c}
1.13 \\
-5.79 \\
9.75 \\
-3.90
\end{array}\right),\left(\begin{array}{l}
\bar{\Delta} f_{i 1} \\
\bar{\Delta} f_{i 2} \\
\bar{\Delta} y_{p 1} \\
\bar{\Delta} y_{p 2}
\end{array}\right)=\left(\begin{array}{c}
0.30 \\
-0.48 \\
8.41 \\
29.06
\end{array}\right), \\
& \left(\begin{array}{l}
\bar{\Delta} w_{1} \\
\bar{\Delta} w_{2} \\
\bar{\Delta} R_{1} \\
\bar{\Delta} R_{2}
\end{array}\right)=\left(\begin{array}{c}
0.12 \\
-0.48 \\
0.95 \\
-5.79
\end{array}\right),\left(\begin{array}{l}
\bar{\Delta} c_{1} \\
\bar{\Delta} c_{2} \\
\bar{\Delta} l_{1} \\
\bar{\Delta} l_{2}
\end{array}\right)=\left(\begin{array}{c}
0.12 \\
-0.48 \\
-0.82 \\
5.63
\end{array}\right) .
\end{aligned}
$$

We increase $\tau_{i 2}$ from 3 percent to 4 percent. As the tax rate is increased, the industrial output, total capital employed by the economy, and the total wealth are reduced. The wage rate, consumption per capita, wealth per capita, output per labor force and public expenditure per capita in region 2 are increased. In region 1 the wage rate, consumption per capita, wealth per capita, and output per labor force are reduced. As region 1's population is reduced, its land rent falls and lot size rises. A main differentce between the effects of increasing the two regions' tax rates is that as region 1's (2's) tax rate on the industrial sector is increased, the national industrial output, national capital employed by the economy, and the national wealth are increased (reduced). This occurs partly because the direction of labor migration is the opposite in the two cases.

$$
\begin{aligned}
& \tau_{i 2}: 0.03 \Rightarrow 0.04, \bar{\Delta} F=-065, \\
& \bar{\Delta} K=-0.64, \bar{\Delta} \bar{K}=-0.66, \bar{\Delta} B=-0.78, \\
& \bar{\Delta} \bar{k}_{1}=-0.18, \bar{\Delta} \bar{k}_{2}=1.64,
\end{aligned}
$$

$$
\begin{aligned}
& \left(\begin{array}{l}
\bar{\Delta} N_{1} \\
\bar{\Delta} N_{i 1} \\
\bar{\Delta} N_{p 1}
\end{array}\right)=\left(\begin{array}{l}
-2.01 \\
-2.01 \\
-2.01
\end{array}\right),\left(\begin{array}{l}
\bar{\Delta} N_{2} \\
\bar{\Delta} N_{i 2} \\
\bar{\Delta} N_{p 2}
\end{array}\right)=\left(\begin{array}{l}
12.92 \\
11.96 \\
32.80
\end{array}\right), \\
& \left(\begin{array}{l}
\bar{\Delta} K_{1} \\
\bar{\Delta} K_{i 1} \\
\bar{\Delta} K_{p 1}
\end{array}\right)=\left(\begin{array}{l}
-2.19 \\
-2.19 \\
-2.19
\end{array}\right),\left(\begin{array}{l}
\bar{\Delta} K_{2} \\
\bar{\Delta} K_{i 2} \\
\bar{\Delta} K_{p 2}
\end{array}\right)=\left(\begin{array}{l}
15.44 \\
13.79 \\
34.97
\end{array}\right), \\
& \left(\begin{array}{l}
\bar{\Delta} F_{i 1} \\
\bar{\Delta} F_{i 2} \\
\bar{\Delta} F_{p 1} \\
\bar{\Delta} F_{p 2}
\end{array}\right)=\left(\begin{array}{l}
-2.19 \\
14.97 \\
-1.46 \\
22.56
\end{array}\right),\left(\begin{array}{l}
\bar{\Delta} f_{i 1} \\
\bar{\Delta} f_{i 2} \\
\bar{\Delta} y_{p 1} \\
\bar{\Delta} y_{p 2}
\end{array}\right)=\left(\begin{array}{c}
-0.18 \\
1.82 \\
0.12 \\
17.04
\end{array}\right), \\
& \left(\begin{array}{l}
\bar{\Delta} w_{1} \\
\bar{\Delta} w_{2} \\
\bar{\Delta} R_{1} \\
\bar{\Delta} R_{2}
\end{array}\right)=\left(\begin{array}{c}
-0.18 \\
1.64 \\
-2.19 \\
14.76
\end{array}\right),\left(\begin{array}{l}
\bar{\Delta} c_{1} \\
\bar{\Delta} c_{2} \\
\bar{\Delta} l_{1} \\
\bar{\Delta} l_{2}
\end{array}\right)=\left(\begin{array}{c}
-0.18 \\
1.64 \\
2.05 \\
-11.44
\end{array}\right) .
\end{aligned}
$$

We now study the impact of changes in the congestion parameter, $\theta_{c}$. We increase the parameter value from 0.05 to 0.06 . The effects are listed in (33). As the congestion effect of public goods becomes stronger, most of the economic variables are negatively affected. It should be noted that although region 1 's population is increased, the region's total capital and output are reduced. The economic loss caused by the strengthened congestion dominates the economic gain brought about by the labor increase.

$$
\begin{aligned}
& \theta_{c}: 0.05 \Rightarrow 0.06, \bar{\Delta} F=-3.03, \\
& \bar{\Delta} K=-3.02, \bar{\Delta} \bar{K}=-3.03, \bar{\Delta} B=-3,09, \\
& \bar{\Delta} \bar{k}_{1}=-3.19, \bar{\Delta} \bar{k}_{2}=-4.09, \\
& \left(\begin{array}{l}
\bar{\Delta} N_{1} \\
\bar{\Delta} N_{i 1} \\
\bar{\Delta} N_{p 1}
\end{array}\right)=\left(\begin{array}{l}
0.72 \\
0.72 \\
0.72
\end{array}\right),\left(\begin{array}{l}
\bar{\Delta} N_{2} \\
\bar{\Delta} N_{i 2} \\
\bar{\Delta} N_{p 2}
\end{array}\right)=\left(\begin{array}{l}
-4.64 \\
-4.64 \\
-4.64
\end{array}\right), \\
& \left(\begin{array}{l}
\bar{\Delta} K_{1} \\
\bar{\Delta} K_{i 1} \\
\bar{\Delta} K_{p 1}
\end{array}\right)=\left(\begin{array}{l}
-2.49 \\
-2.49 \\
-2.49
\end{array}\right),\left(\begin{array}{l}
\bar{\Delta} K_{2} \\
\bar{\Delta} K_{i 2} \\
\bar{\Delta} K_{p 2}
\end{array}\right)=\left(\begin{array}{l}
-8.64 \\
-8.64 \\
-8.64
\end{array}\right), \\
& \left(\begin{array}{l}
\bar{\Delta} F_{i 1} \\
\bar{\Delta} F_{i 2} \\
\bar{\Delta} F_{p 1} \\
\bar{\Delta} F_{p 2}
\end{array}\right)=\left(\begin{array}{l}
-2.49 \\
-8.54 \\
-0.47 \\
-4.48
\end{array}\right),\left(\begin{array}{l}
\bar{\Delta} f_{i 1} \\
\bar{\Delta} f_{i 2} \\
\bar{\Delta} y_{p 1} \\
\bar{\Delta} y_{p 2}
\end{array}\right)=\left(\begin{array}{l}
-3.19 \\
-4.09 \\
-0,18 \\
1.64
\end{array}\right), \\
& \left(\begin{array}{l}
\bar{\Delta} w_{1} \\
\bar{\Delta} w_{2} \\
\bar{\Delta} R_{1} \\
\bar{\Delta} R_{2}
\end{array}\right)=\left(\begin{array}{l}
-3.19 \\
-4.09 \\
-2.49 \\
-8.54
\end{array}\right),\left(\begin{array}{l}
\bar{\Delta} c_{1} \\
\bar{\Delta} c_{2} \\
\bar{\Delta} l_{1} \\
\bar{\Delta} l_{2}
\end{array}\right)=\left(\begin{array}{l}
-3.19 \\
-4.09 \\
-0.72 \\
4.87
\end{array}\right) .
\end{aligned}
$$


We now study the impact of changes in the externality parameter, $\theta_{e}$. We increase the parameter value from 0.03 to 0.04 The effects are listed in (34). As positive externalities become stronger, the industrial output, total capital employed by the economy, and the total wealth are increased. Region 1's population is increased. Also the labor of each sector in region 1 is increased. The wage rate, consumption level and wealth per capita in region 1 are increased. The lot size in region 1 is reduced and the region's housing rent is increased. The effects on those corresponding variables in region 2 are the opposite.

$$
\begin{aligned}
& \theta_{e}: 0.03 \Rightarrow 0.04, \bar{\Delta} F=10.74, \\
& \bar{\Delta} K=10.86, \bar{\Delta} \bar{K}=10.67, \bar{\Delta} B=9.85, \\
& \bar{\Delta} \bar{k}_{1}=7.31, \bar{\Delta} \bar{k}_{2}=-9.44, \\
& \left(\begin{array}{l}
\bar{\Delta} N_{1} \\
\bar{\Delta} N_{i 1} \\
\bar{\Delta} N_{p 1}
\end{array}\right)=\left(\begin{array}{c}
10.76 \\
10.76 \\
10.76
\end{array}\right),\left(\begin{array}{l}
\bar{\Delta} N_{2} \\
\bar{\Delta} N_{i 2} \\
\bar{\Delta} N_{p 2}
\end{array}\right)=\left(\begin{array}{l}
-69.13 \\
-69.13 \\
-69.13
\end{array}\right), \\
& \left(\begin{array}{l}
\bar{\Delta} K_{1} \\
\bar{\Delta} K_{i 1} \\
\bar{\Delta} K_{p 1}
\end{array}\right)=\left(\begin{array}{c}
18.85 \\
18.85 \\
18.85
\end{array}\right),\left(\begin{array}{l}
\bar{\Delta} K_{2} \\
\bar{\Delta} K_{i 2} \\
\bar{\Delta} K_{p 2}
\end{array}\right)=\left(\begin{array}{l}
-72.95 \\
-72.95 \\
-72.95
\end{array}\right), \\
& \left(\begin{array}{l}
\bar{\Delta} F_{i 1} \\
\bar{\Delta} F_{i 2} \\
\bar{\Delta} F_{p 1} \\
\bar{\Delta} F_{p 2}
\end{array}\right)=\left(\begin{array}{c}
18.85 \\
-72.05 \\
9.71 \\
-57.37
\end{array}\right),\left(\begin{array}{l}
\bar{\Delta} f_{i 1} \\
\bar{\Delta} f_{i 2} \\
\bar{\Delta} y_{p 1} \\
\bar{\Delta} y_{p 2}
\end{array}\right)=\left(\begin{array}{c}
7.31 \\
-9.45 \\
-3.19 \\
-4.09
\end{array}\right), \\
& \left(\begin{array}{l}
\bar{\Delta} w_{1} \\
\bar{\Delta} w_{2} \\
\bar{\Delta} R_{1} \\
\bar{\Delta} R_{2}
\end{array}\right)=\left(\begin{array}{c}
7.31 \\
-9.45 \\
18.85 \\
-72.05
\end{array}\right),\left(\begin{array}{l}
\bar{\Delta} c_{1} \\
\bar{\Delta} c_{2} \\
\bar{\Delta} l_{1} \\
\bar{\Delta} l_{2}
\end{array}\right)=\left(\begin{array}{c}
7.31 \\
-9.45 \\
-9.971 \\
223.93
\end{array}\right) .
\end{aligned}
$$

We now study the impact of changes in the parameter, $v_{h}$. We increase the parameter value from 0.05 to 0.06 The effects are listed in (35). As households are more strongly affected by the supply level of public goods, like a rise in the value of positive externalities, the industrial output, total capital employed by the economy, and the total wealth are increased. Region 1's population is increased. Also the labor of each sector in region 1 is increased. The wage rate, consumption level and wealth per capita in region 1 are increased. The lot size in region 1 is reduced and the region's housing rent is increased.

$$
\begin{aligned}
& v_{h}: 0.05 \Rightarrow 0.06, \bar{\Delta} F=2.24, \\
& \bar{\Delta} K=2.30, \bar{\Delta} \bar{K}=2.21, \bar{\Delta} B=1.78, \\
& \bar{\Delta} \bar{k}_{1}=0.50, \bar{\Delta} \bar{k}_{2}=-4.09,
\end{aligned}
$$

$$
\begin{aligned}
& \left(\begin{array}{l}
\bar{\Delta} N_{1} \\
\bar{\Delta} N_{i 1} \\
\bar{\Delta} N_{p 1}
\end{array}\right)=\left(\begin{array}{c}
5.87 \\
5.87 \\
5.87
\end{array}\right),\left(\begin{array}{l}
\bar{\Delta} N_{2} \\
\bar{\Delta} N_{i 2} \\
\bar{\Delta} N_{p 2}
\end{array}\right)=\left(\begin{array}{c}
-37.73 \\
-37.73 \\
-37.73
\end{array}\right), \\
& \left(\begin{array}{l}
\bar{\Delta} K_{1} \\
\bar{\Delta} K_{i 1} \\
\bar{\Delta} K_{p 1}
\end{array}\right)=\left(\begin{array}{c}
6.41 \\
6.41 \\
6.41
\end{array}\right),\left(\begin{array}{l}
\bar{\Delta} K_{2} \\
\bar{\Delta} K_{i 2} \\
\bar{\Delta} K_{p 2}
\end{array}\right)=\left(\begin{array}{l}
-40.27 \\
-40.27 \\
-40.27
\end{array}\right), \\
& \left(\begin{array}{l}
\bar{\Delta} F_{i 1} \\
\bar{\Delta} F_{i 2} \\
\bar{\Delta} F_{p 1} \\
\bar{\Delta} F_{p 2}
\end{array}\right)=\left(\begin{array}{c}
6.41 \\
-40.27 \\
4.23 \\
-29.11
\end{array}\right),\left(\begin{array}{l}
\bar{\Delta} f_{i 1} \\
\bar{\Delta} f_{i 2} \\
\bar{\Delta} y_{p 1} \\
\bar{\Delta} y_{p 2}
\end{array}\right)=\left(\begin{array}{c}
0.50 \\
-4.09 \\
7.31 \\
-9.45
\end{array}\right), \\
& \left(\begin{array}{l}
\bar{\Delta} w_{1} \\
\bar{\Delta} w_{2} \\
\bar{\Delta} R_{1} \\
\bar{\Delta} R_{2}
\end{array}\right)=\left(\begin{array}{c}
0.50 \\
-4.09 \\
6.41 \\
-40.27
\end{array}\right),\left(\begin{array}{l}
\bar{\Delta} c_{1} \\
\bar{\Delta} c_{2} \\
\bar{\Delta} l_{1} \\
\bar{\Delta} l_{2}
\end{array}\right)=\left(\begin{array}{c}
0.50 \\
-4.09 \\
-5.55 \\
60.58
\end{array}\right) .
\end{aligned}
$$

\section{Conclusions}

This paper proposed a two-region growth model with capital accumulation, amenity and regional public good with congestion under assumptions of profit maximization, utility maximization, and perfect competition. We emphasize effects of congestion and various fiscal policies on long-term economic growth and economic geography. We simulated the model with the Cobb-Douglas production functions and demonstrated the existence of a unique equilibrium point. Our comparative statics analysis provides some important insights. For instance, a main difference between the effects of increasing the two regions' tax rates on the output is that as region 1's (2's) tax rate on the industrial sector is increased, the national industrial output, national capital employed by the economy, and the national wealth are increased (reduced).

\section{References}

[1] H. W. Richardson, "Regional Growth Theory," Macmillan, London, 1977.

[2] M. Fujita, P. Krugman and A. Venables, "The Spatial Economy," MIT Press, Cambridge, 1999.

[3] Y. Higano, P. Nijkamp and J. Poot, Eds., "The Region in the New Economy: An International Perspective on Regional Dynamics in the $21^{\text {st }}$ Century," Ashagate, London, 2002.

[4] J. V. Henderson and H. G. Wang, "Urbanization and City Growth: The Role of Institutions," Regional Science and Urban Economics, Vol. 37, No. 5, 2007, pp. 283-313.

[5] W. B. Zhang, "International Trade Theory: Capital, Kno- 
wledge, Economic Structure, Money and Prices over Time and Space," Springer, Berlin, 2008.

[6] W. Isard, "Some Empirical Results and Problems of Regional Input-Output Analysis," In: W. Leontief, et al., Studies in the Structure of the American Economy, Oxford University Press, New York, 1953.

[7] G. J. D. Hewings and R. C. Jensen, "Regional, Interregional and Multiregional Input-Output Analysis," In: P. Nijkamp, Ed., Handbook of Regional and Urban Economics, North-Holland, Amsterdam, 1986.

[8] D. F. Batten, "The Interregional Linkages between National and Regional Input-Output Models," International Regional Science Review, Vol. 7, No. 1, 1982, pp. 53-67.

[9] P. Boomsma and J. Oosterhaven, "A Double-Entry Method for the Construction of Bi-Regional Input-Output Tables," Journal of Regional Science, Vol. 32, No. 3, 1992, pp. 269-284.

[10] P. Canning and Z. Wang, "A Flexible Mathematical Programming Model to Estimate Interregional Input-Output Accounts," Journal of Regional Science, Vol. 45, No. 3, 2005, pp. 539-563.

[11] J. Parr and G. Hewings, "Spatial Interdependence in a Metropolitan Setting," Spatial Economic Analysis, Vol. 2, No. 1, 2007, pp. 8-22.

[12] E. A. Haddad, J. Bonet, G. J. D. Hewings and F. S. Pero- belli, "Spatial Aspects of Trade Liberalization in Combia: General Equilibrium Approach," Banco de la Republica de Colombia, Borradores de Economia, 2008.

[13] W. B. Zhang, "A Multi-Region Model with Capital Accumulation and Endogenous Amenities," Environment and Planning A, Vol. 39, No. 9, 2007, pp. 2248-2270.

[14] T. Eicher and S. Turnovsky, "Scale, Congestion and Growth," Economica, Vol. 67, No. 267, 2000, pp. 325-346.

[15] M. A. Gómez, "Fiscal Policy, Congestion, and Endogenous Growth," Journal of Public Economic Theory, Vol. 10, No. 1, 2008, pp. 595-622.

[16] Y. Kanemoto, "Theories of Urban Externalities," NorthHolland, Amsterdam, 1980.

[17] O. Hochman, "Land Rents, Optimal Taxation and Local Fiscal Independence in an Economy with Local Public Goods," Journal of Public Economics, Vol. 15, No. 2, 1981, pp. 59-85.

[18] W. B. Zhang, "Economic Growth Theory," Ashgate, Hampshire, 2005.

[19] D. Miles and A. Scott, "Macroeconomics - Understanding the Wealth of Nations," John Wiley Sons, Ltd., Chichester, 2005.

[20] A. Abel, B. S. Bernanke and D. Croushore, "Macroeconomics," Prentice Hall, New Jersey, 2007. 